\title{
Minithoracotomy Versus Thoracoscopic Pulmonary Wedge Resection in Interstitial Lung Diseases
}

\author{
Mohammad Reza Farahnak ${ }^{1}$; Karim Beiytsayah ${ }^{2}$; Nader Saki ${ }^{3, *}$ \\ ${ }^{1}$ Department of Surgery, Imam Khomeini Hospital, Ahvaz Jundishapur University of Medical Sciences, Ahvaz, IR Iran \\ ${ }^{2}$ Ahvaz Jundishapur University of Medical Sciences, Ahvaz, IR Iran \\ ${ }^{3}$ Health Research Institute, Hearing Research Center, Ahvaz Jundishapur University of Medical Sciences, Ahvaz, IR Iran \\ ${ }^{*}$ Corresponding author: Nader Saki, Health Research Institute, Hearing Research Center, Ahvaz Jundishapur University of Medical Sciences, Ahvaz, IR Iran. Tel/Fax: +98-6113367562, \\ E-mail:ahvaz.ent@gmail.com
}

Received: November 25, 2014; Accepted: December 2, 2014

\begin{abstract}
Background: Lung biopsy is the gold standard for definitive diagnosis of interstitial lung diseases(ILD). A biopsy is usually performed by non-anatomical wedge resection as an open or thoracoscopy approach.

Objectives: We aimed to compare minithoracotomy approach with thoracoscopy in ILD.

Patients and Methods: Overall, 43 patients with ILD who had referred to Imam Khomeini Hospital for open lung biopsy from 2008 to 2013, were enrolled, and their clinical findings, chest radiography, high resolution computed tomography (HRCT) and spirometry were considered before referral.

Results: A total of 43 (12 males and 31 females, with mean age of $41.90 \pm 8.64$ years) patients underwent minithoracotomy for open lung biopsy. Minithoracotomy mortality rate was $0 \%$ compared to the 0 - $5.2 \%$ reported for thoracoscopy. The mean hospital stay for minithoracotomy was $2.3 \pm 0.97$ days compared to $4.9 \pm 1.53$ days reported for thoracoscopy $(\mathrm{P}<0.05)$. The complication rate was $0.05 \%$ and mean length of operation time was 35 minutes.

Conclusions: Minithoracotomy had fewer complications, shorter length of operation and no operative mortality compared to thoracoscopy. Minithoracotomy may be the method of choice even in patients with severe shortness of breath.
\end{abstract}

Keywords: Lung Diseases; Thoracotomy; Chest Tube; Thoracoscopy

\section{Background}

Interstitial lung disease (ILD) is a common cause of dyspnea with an incidence rate of 25.8 per 100000 individuals (1). Although medical treatment of ILD is almost the same, pathological subtyping helps clinicians accurately predict the prognosis and estimate the lung transplantation date $(2,3)$. Given the diversity of ILD, lung biopsy is required for definitive diagnosis $(4,5)$, which is usually performed by non-anatomical wedge resection. Wedge resection may be performed as an open or thoracoscopy approach. With respect to limitations including, the respiratory reserve in ILD patients, the need for one-lung ventilation and full lateral thoracotomy position in the thoracoscopy method, and declining respiratory ventilation after thoracotomy, some patients lose this diagnostic option.

\section{Objectives}

We aimed to compare the minithoracotomy approach with thoracoscopy for ILD.

\section{Patients and Methods}

This study included 43 patients, with the diagnosis of
ILD based on clinical findings, chest radiography, and high resolution computed tomography (HRCT) and spirometry, who were referred for open lung biopsy by a pulmonologist. This study was conducted at Imam Khomeini Hospital of Ahvaz from 2008 to 2013. The study was approved by Ahvaz Jundishapur University of Medical Sciences Ethical Committee. Inclusion criteria: all patients with clinical diagnosis of ILD were included.

\subsection{Exclusion Criteria}

All patients with a low life expectancy were excluded. Patients had varying degrees of dyspnea. Two patients were under mechanical ventilation. Patients were studied in terms of hospital stay, time to extract the chest tube, delayed chest pain (up to six months), wound infections, air leak, pneumothorax and death.

\subsection{Surgical Technique}

Patients were routinely placed in the right semi-lateral position except in cases that sampling from the left side had been recommended by a pulmonologist. A total of 35 (10 males and 25 females) (81\%) and eight (two males and six females) (19\%) patients were operated on the right and left side, respectively. After general anesthesia and under

Copyright (C) 2015, Ahvaz Jundishapur University of Medical Sciences. This is an open-access article distributed under the terms of the Creative Commons Attribution-NonCommercial 4.0 International License (http://creativecommons.org/licenses/by-nc/4.0/) which permits copy and redistribute the material just in noncommercial usages, provided the original work is properly cited. 
double lung ventilation an $8 \mathrm{~cm}$ incision beginning 1.5 $\mathrm{cm}$ lateral to chondrosternal junction was made and continued laterally on the upper border of the sixth rib. After opening pleura and entering the chest cavity without rib spreading along, a curved clamp was used to grasp the lung in a way that the long clamp formed the third face of a triangle. After reducing tidal volume, pneumorrhaphy began behind the clamp. The lung was cut and clamp released, and a layer of continuous lock was placed over the pneumorrhaphy line. After placement of the chest tube, the incision was closed. The second day after surgery, patients were discharged with a chest tube and on the fourth day of operation if the appropriate situation was met the chest tube was extracted (Figure 1).

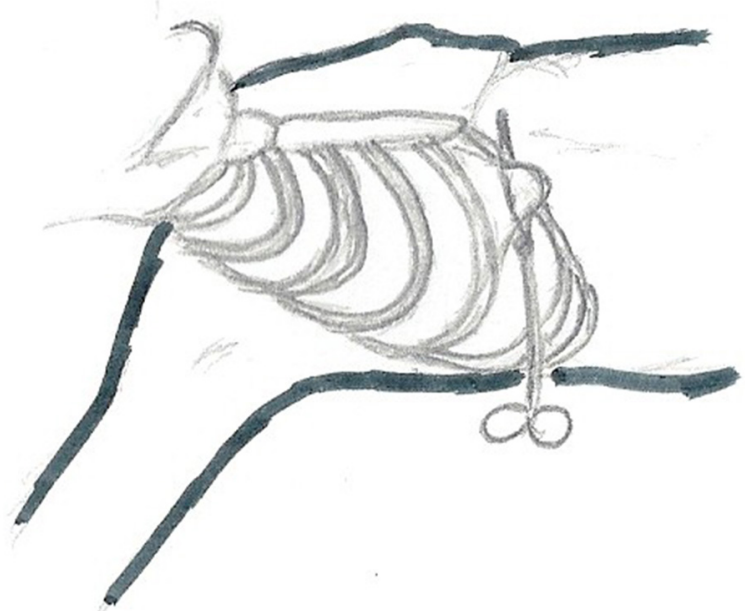

Figure 1. The Technique of Chest Wall Incision

\section{Results}

Of the 43 included patients, 31 (72\%) were female, with a mean age of $41 \pm 9.08$ years and $12(28 \%)$ were male with a mean of $44 \pm 10.03$ years. Age range was between 28 to 65 years with a mean of $41.90 \pm 8.64$ years. Two of the 43 patients $(0.05 \%)$ had complications. Mortality was $0 \%$. The mean hospital stay was 2.3 days and the mean time for extracting the chest tubes was 4.1 days. Two patients, who had preoperative mechanical ventilation with a clear diagnosis of their disease (sarcoidosis), were weaned and discharged after two weeks. One patient went under mechanical ventilation for 48 hours and was discharged on the sixth day without a chest tube. The rest of the patients were routinely discharged on the second day. Chest tubes of one patient were extracted on the eighth day due to a lack of expansion without air leak. The remaining patients were extracted on the fourth day. The mean length of operation was 35 minutes, no other complication was seen and all samples were diagnostic (Table 1). Minithoracotomy mortality rate was $0 \%$ compared to the $0-5.2 \%$ reported for thoracoscopy. The mean hospital stay for minithoracotomy was $2.3 \pm 0.97$ days compared to $4.9 \pm$ 1.53 days reported for thoracoscopy $(\mathrm{P}<0.05)$. The complication rate was $0.05 \%$ and mean length of operation time was 35 minutes (Table 2).

\begin{tabular}{lc}
\hline Table 1. Pathology of Patients \\
\hline Pathological characteristics & No. (\%) \\
\hline Idiopathic pulmonary fibrosis & $10(23)$ \\
Sarcoidosis & $5(11)$ \\
Connective tissue diseases, (RA) & $1(0.02)$ \\
\hline Lymphangioleiomyomatosis & $1(0.02)$ \\
Eosinophilic lung diseases & $1(0.02)$ \\
Hypersensitivity pneumonitis & $17(39)$ \\
Interstitial lung diseases (occupational) & $7(16)$ \\
Lymphangitic carcinomatosis & $1(0.02)$ \\
\hline
\end{tabular}

Table 2. Information on Thoracoscopy and Minithoracotomy

\begin{tabular}{lcc}
\hline & Thoracoscopy & Minithoracotomy \\
\hline Hospital stay, $\mathbf{d}$ & $4.9 \pm 1.53$ & $2.3 \pm 0.97^{\mathrm{a}}$ \\
$\begin{array}{l}\text { Chest tube, } \mathbf{d} \\
\begin{array}{l}\text { Length of operation } \\
\text { time, min }\end{array}\end{array}$ & - & 4.1 \\
Pneumothorax & 25 & 35 \\
Mortality & $0-5.2$ & 0 \\
Complications & $9.6-19$ & 0 \\
\hline a & & 0.05 \\
\hline
\end{tabular}

\section{Discussion}

In one study complication rate in the thoracoscopic approach was 9.47 (19\%) (6), yet in another study this was $9.6 \%(4,5)$. In the thoracoscopic procedure the mean hospital stay was $4.9 \pm 1.53$ days, chest tube drainage was similar, and the mean length of the operation was 93 minutes (6). Our study showed that mini-thoracotomy for wedge resection has fewer mortality, complication and shorter length of operation time and is recommended for ILD patients. In the literature, pneumothorax was reported for $25 \%$ of cases (7) and a second surgery due to remaining pneumothorax was performed for $3 \%$ of cases (8). Our study showed that minithoracotomy for wedge resection was associated with no pneumothorax and second surgery due to remaining pneumothorax. Different studies have reported the mortality rate of thoracoscopic procedures as $2.1 \%(4,5), 5.2 \%(7)$ and $0.06 \%(6)$, while our study indicated a $0.0 \%$ mortality rate. In conclusion, minithoracotomy may be considered as an effective alternative for the treatment and diagnosis of intra-thoracic diseases, with the advantage of causing less lung dysfunction. This aspect is especially important in ILD patients who usually present a restrictive pattern in preoperative pulmonary function tests (PFTs). Furthermore, this approach is asso- 
ciated with a lower rate of postoperative complications, less hospital stay and less mortality rate.

\section{References}

1. Musellim B, Okumus G, Uzaslan E, Akgun M, Cetinkaya E, Turan O, et al. Epidemiology and distribution of interstitial lung diseases in Turkey. Clin RespirJ. 2014;8(1):55-62.

2. Caminati A, Harari S. IPF: New insight in diagnosis and prognosis. Respir Med. 2010;104 Suppl 1:S2-10.

3. Nathan SD, Shlobin OA, Weir N, Ahmad S, Kaldjob JM, Battle E, et al. Long-term course and prognosis of idiopathic pulmonary fibrosis in the new millennium. Chest. 2011;140(1):221-9.

4. Kayatta MO, Ahmed S, Hammel JA, Fernandez F, Pickens A, Miller D, et al. Surgical biopsy of suspected interstitial lung disease is superior to radiographic diagnosis. Ann Thorac Surg.
2013;96(2):399-401

5. Nguyen W, Meyer KC. Surgical lung biopsy for the diagnosis of interstitial lung disease: a review of the literature and recommendations for optimizing safety and efficacy. Sarcoidosis Vasc Diffuse Lung Dis. 2013;30(1):3-16.

6. Ferson PF, Landreneau RJ, Dowling RD, Hazelrigg SR, Ritter P, Nunchuck S, et al. Comparison of open versus thoracoscopic lung biopsy for diffuse infiltrative pulmonary disease. J Thorac Cardiovasc Surg. 1993;106(2):194-9.

7. Luo Q, Han Q, Chen X, Xie J, Wu L, Chen R. The diagnosis efficacy and safety of video-assisted thoracoscopy surgery (VATS) in undefined interstitial lung diseases: a retrospective study. J Thorac Dis. 2013;5(3):283-8.

8. Tomasdottir GF, Torfason B, Isaksson H], Gudbjartsson T. [Comparison of video-assisted thoracoscopic surgery and limited axillary thoracotomy for spontaneous pneumothorax]. Laeknabladid. 2007;93(5):405-12. 